\title{
Ensino remoto em tempos de pandemia: relatos de docentes de cursos de Relações Públicas no Brasil
}

\author{
Remote teaching during the pandemia: narratives of brazilian \\ undergraduate Public Relations faculty
}

\section{Enseñanza remota en tiempos de pandemia: relatos de docentes de carreras de Relaciones Públicas en Brasil}

Maria Aparecida Ferrari'

https://orcid.org/0000-000I-6873-607I

Karina Ferrara Barros²

https://orcid.org/0000-000I-7243-4375

\begin{abstract}
Resumo: $O$ presente relato tem como objetivo apresentar as dificuldades enfrentadas pelos docentes de cursos de Relações Públicas no Brasil com o ensino remoto no período da pandemia, uma vez que o isolamento social para conter o avanço da Covid-19 obrigou as IES e escolas que rapidamente adaptassem os conteúdos das disciplinas para o ensino remoto com o uso da tecnologia digital. Foram coletadas opiniões de 121 docentes por meio de uma sondagem e os resultados foram agrupados em quatro temas relacionados às dificuldades dos docentes: a)(des)conhecimento e adaptação ao uso das ferramentas digitais, b)(des)interesse e posicionamento dos alunos ao ensino remoto, c)atuação dos docentes no ambiente residencial, e d)ausência de capacitação e/ou orientação das IES aos docentes. Concluiu-se que, apesar das dificuldades enfrentadas, os docentes exerceram papel fundamental na continuidade das aulas dos cursos de Relações Públicas mesmo com o acúmulo de tarefas laborais, domésticas e familiares.
\end{abstract}

Palavras-chave: Ensino remoto. Plataformas digitais. Relações Públicas. Ensino-aprendizagem. Capacitação docente.

\begin{abstract}
The study presents the challenges met by Public Relations faculty during the deployment of remote teaching formats required by the social distancing imposed by the COVIDI9 pandemic, and the adaptations of contents required by the full utilization digital technologies. The opinions of $12 \mid$ Public Relations faculty were ascertained through the use of a survey grouped in accordance with four challenges encountered, namely: (a) familiarity and adaptation to the use of digital technologies; (b) the interest and lack of interest shown by students to the remote teaching format; (c) teaching behavior in the home environment; (d) missing training and/or

\footnotetext{
' Livre-docente pela Universidade de São Paulo (USP). Doutora e mestre em Ciências da Comunicação pela Universidade de São Paulo (USP). Professora Associada I da Escola de Comunicações e Artes da Universidade de São Paulo (ECA-USP) nos Programas de Pós-graduação e Graduação. ECA-USP. E-mail: maferrar@usp.br

${ }^{2}$ Graduada em Comunicação Social com habilitação em Relações Públicas pela Escola de Comunicações e Artes da Universidade de São Paulo (ECA-USP). Mestranda em Ciências da Comunicação pela Universidade de São Paulo (USP). ECA-USP. E-mail: karina.barros@usp.br
} 
guidance given by the institution of higher education. It was concluded that despite the challenges encountered, Public Relations faculty demonstrated a fundamental role in the continuity of PR teaching programs despite the over burdening of domestic, work-related and family issues.

Keywords: Remote learning. Digital platforms. Public Relations. Teaching-learning process. Faculty training.

Resumen: El presente informe tiene como objetivo presentar las dificultades de los docentes de las carreras de Relaciones Públicas en Brasil con la enseñanza remota en el período de la crisis sanitaria, ya que el aislamiento social para contener el avance del Covid-19 obligó a las IES y los colegios a adaptar rápidamente los contenidos de las asignaturas con el uso de la tecnología digital. Se recogieron opiniones de 121 docentes a través de una encuesta y los resultados se agruparon en cuatro temas relacionados con las dificultades de los docentes: a) (des) conocimiento y adaptación al uso de herramientas digitales, b) (des) interés y posicionamiento de los estudiantes hacia enseñanza a distancia, c) presencia de los profesores en el entorno residencial, y d) ausencia de capacitación y/o orientación de las IES a los profesores. Se concluyó que, a pesar de las dificultades enfrentadas, los docentes tuvieron un papel fundamental en la continuidad de las clases en las carreras de Relaciones Públicas, a pesar del acumulo de tareas laborales, domésticas y familiares.

Palabras-clave: Enseñanza remota. Plataformas digitales. Relaciones Públicas. Enseñanza-aprendizaje. Capacitación docente.

\section{Introdução}

Na segunda semana do mês de março de 2020 , as instituições públicas e privadas de educação no Brasil foram surpreendidas com a suspensão das aulas presenciais em decorrência da pandemia da Covid-19. Essa situação interrompeu os processos de ensino-aprendizagem em andamento, impediu a interação e vivência de alunos e docentes propiciadas pelos contextos das escolas e universidades além de ocasionar o desmonte da rotina dos docentes, estudantes e de suas famílias.

Quase imediatamente professores de todos os níveis de ensino foram obrigados a reorganizar os conteúdos programáticos de suas disciplinas para disponibilizá-los nas plataformas digitais, aplicativos e redes para dar continuidade às aulas nesse período. $O$ assunto foi abordado na publicação de Harada (2020) e em pesquisa do Instituto Península (2020) sobre a educação básica.

A pandemia escancarou problemas já existentes, como a falta de capacitação dos docentes pelas IES e, como consequência, o uso regular de plataformas como apoio para as aulas. $O$ ensinoaprendizagem e as metodologias ativas nos cursos de Relações Públicas no país têm sido objeto de pesquisas (FERRARI, 20I5, 20I7, 20I8; GROHS, 20I7; SANTOS e FERRARI, 20I7; MARTINS, 2019). Em sua pesquisa sobre didática nos cursos de Relações Públicas, Ferrari (2018) mostrou que uma parte dos professores começou a introduzir tecnologias digitais em suas aulas para que os estudantes se sentissem mais motivados e atraídos. Quintanilha (2017, p. 260) esclarece que as práticas diferenciadas ajudam os estudantes a conseguir "autonomia na elaboração de um projeto e na criação de um produto que, é claro, contribui para a incorporação de novas aprendizagens, ou para aprofundar o que já existe".

Assim sendo, o presente relato tem como objetivo apresentar as dificuldades enfrentadas pelos docentes de cursos de Relações Públicas no Brasil com o ensino remoto no período da pandemia. Para tanto, foram coletadas as opiniões de $12 \mathrm{I}$ docentes do referido curso. A sondagem identificou quatro 
temas relacionados às adversidades apresentadas aos docentes e mostrou que os professores exerceram papel fundamental na continuidade das aulas dos cursos de Relações Públicas durante a pandemia. Os resultados serão apresentados no próximo tópico e, ao final, são apresentadas as considerações finais das autoras.

\section{Dificuldades dos docentes dos cursos de Relações Públicas}

Nas últimas décadas a revolução tecnológica afetou sobremaneira todas as Instituições de Ensino Superior (IES), assim como todo o mercado de trabalho no Brasil, tanto em termos de processamento de informações como na geração de conhecimento e uso de Tecnologias de Informação e Comunicação - TICs. O impacto das TICs no sistema educacional traduziu-se no uso de dispositivos educacionais capazes de melhorar a qualidade de educação do estudante, revolucionando a maneira como as informações são obtidas, manipuladas e interpretadas (CASTELLS, 2002).

Ao analisar a atividade profissional de Relações Públicas no Brasil, verificamos que é uma profissão especializada, cujo objetivo central é a manutenção dos relacionamentos da organização com diferentes públicos. Cabe ao profissional ser um analista de cenário capaz de identificar percepções do público em relação à organização e vice-versa (GRUNIG; FERRARI; FRANÇA, 20II). Com o avanço da tecnologia a prática das Relações Públicas passou a incorporar uma série de instrumentos e plataformas digitais que, se por um lado facilitaram o trabalho dos comunicadores, por outro, têm mostrado que as organizações passaram a ser mais vulneráveis em relação à velocidade e instantaneidade das informações, levando a produção e disseminação das "fake news".

Considerando-se o cenário durante o período de distanciamento social, foi realizada uma sondagem com docentes de cursos de Relações Públicas do Brasil, entre os meses de março e abril de 2020, para identificar as dificuldades encontradas na adaptação do ensino presencial para o remoto. Hoje, o Brasil conta com 54 cursos de Relações Públicas no Brasil (INEP, 2019), e de acordo com pesquisa de Ferrari (2018), existem aproximadamente 300 docentes que ministram disciplinas específicas nos referidos cursos do país.

Uma sondagem foi enviada para todos os docentes de cursos de Relações Públicas no Brasil que constavam de listagem atualizada. O questionário online estava composto por 17 questões fechadas e 5 abertas. No período de 20 dias, entre os meses de março e abril de 2020, obtivemos a resposta de 121 respondentes. $O$ total de questionários recebidos se aproximou a $40 \%$ do corpo de professores de todos os cursos de Relações Públicas no Brasil, dado que foi calculado segundo estimativa dos resultados de pesquisa de Ferrari realizada em 2017. Dos 121 respondentes, 36\% atuavam nos cursos de Relações Públicas de IES públicas e 64\% em IES privadas. Do total de participantes, $69 \%$ eram

Olhar de professor, Ponta Grossa, v. 24, p. I-9, e-16015.049, 2021.

Disponível em <https://revistas2.uepg.br/index.php/olhardeprofessor> 
mulheres e $31 \%$ eram homens. Os docentes respondentes tinham idade entre 26 e 73 anos, com média de 47,8 anos.

Analisando as respostas foram elencados quatro temas relacionados às dificuldades encontradas para a realização das aulas pelo sistema remoto: a) (des)conhecimento e adaptação ao uso das ferramentas digitais, b) (des)interesse e posicionamento dos alunos ao ensino remoto, c) atuação do docente no ambiente residencial, e d) ausência de capacitação e/ou orientação dos docentes pelas IES. Vale ressaltar que os resultados obtidos não mostraram diferenças entre os sexos ou tipo de IES.

Os resultados apontaram que uma pequena amostra $(8 \%)$ de respondentes demonstrou confiança na adaptação do ensino presencial para o ensino remoto e nos relatos desse grupo de docentes percebeu-se que as IES apoiaram o corpo docente com capacitação e treinamentos para o ensino remoto. Os docentes que lecionavam em IES que anteriormente à pandemia já utilizavam plataformas digitais mostraram-se mais preparados para lidar com as dificuldades do ensino no período de distanciamento social.

A maioria dos docentes (92\%) mostrou-se mais resistente ao ensino remoto e apontou ausência de colaboração por partes das instituições. Curiosamente a falta de apoio institucional já havia sido mapeada por Ferrari (2018) e os docentes sentiam-se despreparados para $\circ$ uso de novas tecnologias e metodologias ativas. Em algumas IES, segundo os respondentes da presente sondagem, a orientação aos docentes era para replicar o ensino presencial tal qual para o remoto, o que foi considerado impossível pelos docentes, como mostra um dos comentários: "houve uma pressuposição da IES de que apenas deveríamos passar a dar as aulas a distância, como uma simples migração, o que, definitivamente, não é viável”. Em entrevista para a BBC News Brasil (IDOETA, 2020), Fredric Litto ressaltou que "um erro comum é achar que basta gravar a aula do professor e transmiti-la online para fazer os alunos aprenderem". Dessa forma, é evidente a necessidade de adaptação do ensino presencial para o ensino remoto, uma vez que se trata de linguagens e interações distintas entre os dois modelos de ensino-aprendizagem (ZABALZA, 2020).

$\mathrm{Na}$ sequência, apresentaremos cada um dos temas relacionados às dificuldades enfrentadas pelos docentes dos cursos de Relações Públicas no Brasil e suas justificativas:

a) (Des)conhecimento e adaptação ao uso das ferramentas digitais - $O$ correspondente a $54 \%$ das respostas dos docentes indicou que o processo de transição do ensino presencial para o remoto foi a principal dificuldade encontrada, seja devido ao pouco tempo disponível para a reestruturação dos conteúdos e, também, na definição sobre qual plataforma digital utilizar. A afirmação de um respondente ilustra a situação: "percebi que deveria modificar o tempo de duração da aula, a forma de interação com os estudantes, a formulação dos exercícios práticos e os canais de feedback". Outro problema detectado foi a escolha da plataforma a ser utilizada para as aulas, levando em 
consideração o grande número de alunos por turma, uma vez que os docentes não contavam com experiências anteriores no ensino remoto. Além disso, os docentes demonstraram preocupação especial em relação ao controle de presença, desenvolvimento das atividades em grupo durante as aulas, promoção de debates e de formas de avaliação.

b) (Des)interesse e posicionamento dos alunos ao ensino remoto - Aproximadamente $24 \%$ das respostas apontaram como dificuldade no ensino remoto a resistência e/ou falta de motivação dos alunos. Sobre o assunto, um dos docentes reforçou que "apesar de ser uma geração que já nasceu em contato com o mundo digital, há uma grande resistência ao modelo de aprendizagem apoiado $100 \%$ no uso da tecnologia". Por outro lado, pesquisa realizada por Ferrari (2018), apontou utilização de ferramentas digitais no ensino de Relações Públicas pelos docentes. Talvez a dissonância entre o uso da tecnologia pelo professor e a falta de interesse dos alunos tenha sido uma situação particular, haja visto que a mudança de modelos de ensino ocorreu de forma brusca.

Paralelamente, os docentes mencionaram suas preocupações com $\circ$ uso de ferramentas digitais, principalmente em como a aprendizagem do conteúdo seria assimilada pelos estudantes. A afirmação de Litto legitima a preocupação dos professores quando afirma que "na verdade o ensino remoto é mais difícil, porque depende da motivação e da maturidade do aluno em se dedicar o suficiente aos estudos sem a presença física dos docentes" (IDOETA, 2020). Ainda que exista esforço e dedicação dos professores para manter a qualidade do ensino, foi observado o desinteresse dos estudantes, principalmente nas atividades que não são avaliadas para composição das notas finais das disciplinas. Um dos professores reforçou que "eles [os alunos] deixam a sua fotografia e vão tomar banho, ver TV. Quando você chama algum estudante, culpam a conexão, o microfone... A gente fala para o nada e $o$ ninguém".

Outro professor compartilhou a experiência da IES onde leciona, relatando que no início do distanciamento social e da adaptação do ensino remoto, os estudantes não frequentavam as aulas e que a participação aumentou quando ele inseriu o chat e o fórum como meios de ensino. Em contrapartida, também foram reportados casos de alunos que participaram das aulas remotas no início do período de pandemia, mas que a partir de determinado momento deixaram de comparecer aos encontros. O desconhecimento do motivo da abstenção é preocupante e existem diferentes indicativos para a ausência, como problemas de saúde, o contágio pelo vírus Covid-19, ou também a falta de um computador ou cobertura de internet para participar das aulas. Além disso, alguns estudantes declararam viver em ambientes domésticos conturbados, nos quais não se sentiam à vontade para comparecer às aulas virtuais.

c) Atuação do docente no ambiente residencial - A sobrecarga de trabalho, seja devido à adaptação das aulas, assim como de tarefas domésticas, foi abordada por 13\% das respostas dos

Olhar de professor, Ponta Grossa, v. 24, p. I-9, e-16015.049, 2021.

Disponível em <https://revistas2.uepg.br/index.php/olhardeprofessor> 
professores. Para eles, a preparação das aulas remotas demanda mais dedicação e tempo do que a preparação das aulas presenciais. A situação de sobrecarga de afazeres é ainda mais intensa para os docentes do sexo feminino e tal fato é comprovado por estudo do Instituto Brasileiro de Geografia e Estatística - IBGE (PAMPLONA, 2020) que constatou que as mulheres exercem mais tarefas domésticas do que os homens e, dessa forma, têm menos tempo de dedicação ao trabalho. Além disso, - ambiente residencial não favorece a concentração e o excesso de trabalho faz com que haja um desequilíbrio com as demais funções domésticas. A evidência das dificuldades aparece na seguinte afirmação: "interferências do ambiente familiar uma vez que todos estamos no mesmo espaço, sem limitação de diferenciações entre trabalho, família e lazer". Nesse sentido, a fronteira entre casa e a universidade, assim como entre a vida pessoal e o trabalho, foi rompida, contribuindo para uma rotina de trabalho permanentemente intensificada.

d) Capacitação e orientação dos docentes pelas IES - No período da pandemia, $9 \%$ das respostas evidenciaram falta de capacitação ou de orientação por parte das IES. Os respondentes também destacaram que houve mudanças constantes nas orientações fornecidas pelas coordenações dos cursos, o que contribuiu para maior sobrecarga de trabalho. Além disso, as IES pressionaram os professores para a manutenção da qualidade das aulas, principalmente nas IES privadas, nas quais há maior risco de evasão de alunos e, consequentemente de demissão de docentes. Um docente evidenciou tal fato dizendo: "há foco demasiado nos alunos e pouco na saúde mental dos professores".

Uma sugestão indicada nos relatos dos docentes para mitigar as dificuldades encontradas seria contar com equipe da área de Tecnologia da Informação (TI) das IES para auxiliar na capacitação e o esclarecimento de dificuldades relativas ao uso das ferramentas digitais. Segundo um dos professores, "o excesso de tutoriais para lidar com o recurso também colaborou para um processo de transição não produtivo". Nesse sentido, a equipe de TI facilitaria a compreensão dos docentes sobre as ferramentas digitais, o que é imprescindível para a adaptação das aulas para o ensino remoto. A ausência de troca de informações entre os professores também foi indicada como uma dificuldade do ensino remoto. É importante ressaltar que nenhum dos participantes confirmou apoio das IES no sentido de facilitar a comunicação entre os professores. Tendo em vista as dificuldades encontradas pelo corpo docente para a troca de informação entre pares, seria de grande valia compartilhar as experiências de fracasso e de sucesso para a adaptação do ensino remoto e na otimização de processos. Entretanto, para isso é necessário que as IES criem espaços virtuais de convivência entre os docentes.

\section{Considerações finais}

Apresentar as dificuldades enfrentadas pelos docentes de cursos de Relações Públicas no Brasil com o ensino remoto no período de distanciamento social foi o objetivo da pesquisa apresentada. 
Com uma amostra de 121 respondentes chegou-se a quatro temas relacionados às dificuldades dos docentes. Os resultados da pesquisa mostraram que apesar das dificuldades enfrentadas, os docentes exerceram papel fundamental na continuidade das aulas dos cursos de Relações Públicas a despeito do acúmulo de tarefas laborais, domésticas e familiares. Também foi mencionada a falta de capacitação pelas IES, a resistência do corpo discente no ensino completamente mediado por plataformas tecnológicas e a exclusão sofrida por estudantes que não contavam com equipamento digital ou acesso à internet.

Além disso, a sondagem evidenciou a necessidade da reflexão sobre o ensino presencial que estava em curso antes da pandemia, visto que as plataformas digitais e o perfil dos estudantes não estão sendo contemplados nas formas tradicionais de ensino. Assim, o período de distanciamento social escancarou uma realidade que já estava presente no ambiente educacional brasileiro. $O$ uso de novas tecnologias de aprendizagem é um caminho sem volta no ensino pós-pandemia. Por isso, é provável que novas transformações ocorram nas IES públicas e privadas no futuro próximo, assim como nas organizações. Entretanto, trata-se de um grande desafio visto que as desigualdades sociais do Brasil são gritantes e a falta de recursos tecnológicos para alunos e professores, assim como a necessidade de investimento em capacitação dos docentes é urgente.

A crise sanitária trouxe muitos aprendizados e cabe as IES aproveitá-los. Por fim, é importante que o compromisso de docentes com estudantes e com a educação não tenha como contrapartida das IES a retirada de direitos, o controle e a vigilância sobre o trabalho dos professores, a submissão da docência à tecnologia, o acúmulo de atividades e a estafa física e mental. A educação, como eixo fundamental para o desenvolvimento de um país, deve ser prioridade sempre.

\section{Referências}

CASTELLS, M. La dimensión cultural de internet. Instituto de Cultura: debates culturales. UOC y Ajuntamento de Barcelona, 2002. Recuperado de http://www.uoc.edu/culturaxxi/esp/articles/castells0502/castells0502.html. Acesso em: 30 de maio de 2020.

FERRARI, M. A. Didática nos cursos de Relações Públicas: desafios e perspectivas do ensino universitário. Pesquisa desenvolvida com apoio da Fapesp, Eca/USP, 2018.

FERRARI. M. A. Perfil dos cursos de Relações Públicas no Brasil: uma visão dos coordenadores e docentes do processo ensino-aprendizagem. São Paulo. 2017. Tese de Livre-Docência. Escola de Comunicações e Artes. Universidade de São Paulo.

FERRARI, M. A. Perfil dos egressos do curso de Relações Públicas da ECA/USP: análise da trajetória profissional e das percepções do curso. Relatório de Pesquisa. 2015.

GROHS, A. C. C. P. Laboratório de relacionamentos estratégicos: nova metodologia educacional para o ensino-aprendizagem das relações públicas. 2017. Tese (Doutorado em

Olhar de professor, Ponta Grossa, v. 24, p. I-9, e-16015.049, 2021.

Disponível em <https://revistas2.uepg.br/index.php/olhardeprofessor> 
Interfaces Sociais da Comunicação) - Escola de Comunicações e Artes, Universidade de São Paulo, São Paulo, 2017. Doi: 10.1 1606/T.27.20I8.tde-22022018-170555. Acesso em: 04 jun. 2020.

GRUNIG, J. E; FERRARI, M. A; FRANÇA, F. Relações Públicas: teoria, contexto e relacionamentos. São Caetano do Sul: Difusão Editora, 20II.

HARADA, A. Da tela pra cá é diferente: trabalho docente e ensino a distância nas escolas privadas. FEPESP. Federação dos Professores do Estado de São Paulo, 2020. Disponível em: http://fepesp.org.br/artigo/8037. Acesso em: II jun. 2020.

IDOETA, P. A. Os desafios e potenciais da educação à distância, adotada às pressas em meio à quarentena. BBC News Brasil, São Paulo, 17 abr. 2020. Disponível em: https://www.bbc.com/portuguese/brasil-52208723. Acesso em: II jun. 2020.

INEP. Instituto Nacional de Pesquisas Educacionais Anísio Teixeira. Sinopses estatísticas da educação superior - graduação ( 1 995-20l 9). Disponível em < http://portal.inep.gov.br/superiorcensosuperior-sinopse> Acesso em 28/mai./2020.

INSITUTO PENÍNSULA. Pesquisa de sentimento e percepção dos professores brasileiros nos diferentes estágios do Corona vírus no Brasil. 2020. Disponível em: https://www.institutopeninsula.org.br/wp-content/uploads/2020/05/Pulso-Covid-19_-InstitutoPeni\%CC\%8Insula.pdf. Acesso em: 9 jun. 2020.

MARTINS, Juliane. Formação acadêmico-profissional na área de comunicação: as competências como elemento conceitual dessa relação. In: CONGRESSO ABRAPCORP, XIII. [São Paulo, SP, 6-9 maio 2019]. [Anais.]. São Paulo, SP: Abrapcorp, 2019. Disponível em: <http://abrapcorp.org.br/site/manager/arq/(cod2_22668)JulianeMartins_GT7_Abrapcorp2019.pdf>. Acesso em: 20 abr. 2020.

PAMPLONA, N. Mulheres têm mais funções domésticas que homens e menos tempo para trabalho remunerado, diz IBGE. Folha de São Paulo, Rio de Janeiro, 4 jun. 2020. Disponível em: https://wwwl.folha.uol.com.br/mercado/2020/06/mulheres-tem-mais-funcoes-domesticas-quehomens-e-menos-tempo-para-trabalho-remunerado-diz-ibge.shtml?utm_source=mail. Acesso em: 4 jun. 2020.

QUINTANILHA, L. Inovação pedagógica universitária mediada pelo Facebook e YouTube: uma experiência de ensino-aprendizagem direcionado à geração-Z. Educar em Revista, Curitiba, v. 33, n. 65, p. 249-263, jul./set. 2017. Doi: http://dx.doi.org// 0.1590/0104-4060.50027.

SANTOS, C. M. R; FERRARI, M. A. (org.) Aprendizagem ativa: contextos e experiências em comunicação. Bauru: Universidade Estadual Paulista, Faculdade de Arquitetura, Artes e Comunicação, 2017. Disponível em: <https://www.faac.unesp.br/Home/Utilidades/aprendizagem-ativa--versao-digital.pdf>. Acesso em: 20 abr. 2020.

ZABALZA, M. A. A nobre missão dos professores universitários no século $X X I$ : uma visão contemporânea vinda da Espanha. Revista Organicom. Eca/USP, Ano 17, n. 32, jan/abril de 2020. p. $20-28$. 
Recebido em: 15 de junho de 2020.

Versão corrigida recebida em: 29 de setembro de 2020.

Aceito em: 03 de fevereiro de 2021.

Publicado online em: 28 de maio de 2021.

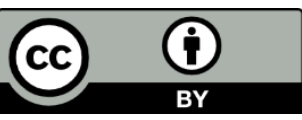

